\title{
Trends of Change and Alternative Models for Existence of Architectural Education
}

\author{
Abraham George $^{1 *}$ and Susan Abraham ${ }^{2}$ \\ ${ }^{1}$ Department of Architecture and Regional Planning, India \\ ${ }^{2}$ Asstistant Executive Engineer, India
}

*Corresponding author: Abraham George, Department of Architecture and Regional Planning, Pin-721302, India

Submission: 眥 August 18, 2017; Published: 制 September 25, 2017

\begin{abstract}
Rapid globalization, changing fluctuating market economy and deteriorating social and climatic conditions have made their imprint on the profession, practice and education in architecture. In practice and profession, the dominance of research and technology, in terms of materials, modeling software, compliance with energy, smart and sustainability standards, and the role of developmental and financial agencies are felt. In academics multicultural and heterogeneous student groups exist in mass education and compounding problems of lack of qualified faculty members, research and almost no participation of industry along with obsolete pedagogy, churn out ill-prepared graduates to address complex design issues. Complexities vary from technological, social, behavioral and age-friendliness, use and management of energy and resources, lack of qualified labor force, changing politics and policies, increasing cost of construction and materials, risk and accidents and creation of sustainable, Age-friendly and smart built forms and infrastructure. Increasing obsolescence levels of contemporary educational systems in terms of pedagogy, instructional tools and academic and support spaces are a matter of immediate concern.

Contemporary architectural education is yet to respond accountably to the needs of multicultural, globalized societies, in imparting learner empowerment. Studies on the problems of classroom communication reveal the importance to develop appropriate graphic tools for classroom communication in order to generate and sustain learner participation and empowerment. This fact remains true in 'diffusion of research and developmental results to general public'. Concerted efforts of professional, research, governmental, and educational institutions are required to impart appropriate education that emphasizes 'learning and empowerment, over teaching' in graduates. Major revamping in pedagogy and research are suggested for imparting relevance and learner empowerment to facilitate long term survival of the profession of architecture.
\end{abstract}

Keywords: Classroom communication; Heterogeneous; Learner empowerment; Interaction; Pre engineered buildings; Pedagogy; Curriculum

\section{Introduction}

Ever increasing globalization, climate change, market economy and deteriorating social conditions have made their imprint on the profession, practice and academics in architecture, as in all walks of life. In practice and profession, the dominance of research and development in science and technology in terms of materials, software modeling, compliance with energy, smartand sustainability standards, and the role of developmental and financial agencies are felt. In academics, the formation of multicultural, heterogeneous student groups in institutions of mass education and lack of qualified faculty, obsolete pedagogy, and research along with almost no participation of industry, churn out ill-prepared graduates who are to address complex issues involved in contemporary design scenario. These complexities vary from technological requirement, user-related issues, use and management of energy and resources, lack of qualified labor force, political and societal issues, increasing cost of construction and materials, avoidance of risk and accidents, tolerance to increasing terrorism and creation of sustainable indoors and built forms. Added to these, the mammoth problems of natural and man-made calamities shatter the contemporary world.
These include tsunami and floods, increasing effects of global warming, massive earthquakes, hurricanes and whirlwinds that occur in different parts of the world. The profession and academics cannot stay watching any further, but react appropriately to the emerging environmental, socio-economic and technological trends.

Unrest that is generated by terrorism and acts of hate demands higher safety and security standards for the contemporary built forms. Surveillance and monitoring with appropriate counter terror facilities and acts of nature-tolerance, poses huge challenges. Ever growing proportion of the elderly population demands a different model in planning and design of built and un-built spaces which requires research and development of age-friendly solutions [1]. Time constraints and resource scarcity push daily life of rich and the poor alike to the edges, resulting in modified or adapted user behavior and needs that need to be addressed in the design of trendy age-friendly built forms and infrastructure. Preparing graduates to address these complex design issues and the spaces require an appropriate pedagogy and academic model. Increasing levels of obsolescence of the contemporary educational systems in 
terms of their pedagogy, instructional tools and quality academic spaces are a matter of immediate concern. India, one of the fastest growing economies with construction activities contributing a lion's share also has contributed to the advancement of philosophy and education, in past and present; however, contemporary architectural education scenario is yet to respond to the needs and self-empowerment of the multicultural, global learners!

Studies reveal the inability of graphics-oriented classroom communication that is to impute transformation power in students in making designs out of abstract thoughts and discourse! Modern trends manifest designs that are more visual, with novel forms unattainable in yesterday's due to the non-availability of computing, modeling and manufacturing technology which is present today. Structures defying gravity and dazzling forms doodles human perception and mind. However, technologically superior designs dominate over the traditional, humane architecture. Preengineered buildings (PEB) command attention of developers since they have the superior product quality and precision over traditional techniques. Along with all advantages of pre-engineered buildings, it also brings forth stereotyping restricting creativity and uniqueness that are central to architecture.

It is acknowledged the power of graphics and word and therefore, the importance to develop appropriate graphic tools for classroom communication in order to generate and sustain learner participation. The situation is not much different in the field, especially when it comes to diffusion of information and fruits of research and development or planning and design to the general public. European Union today faces this challenge in communicating and convincing the 'planning and strategies and benefits' that various research and developmental agencies have brought forth to its beneficiary partner countries.

Role and relevance of professional and statutory regulating bodies in the profession and academics of architecture cannot be ignored any further. Time has come to react to the changing global scenario in terms of positive response including modified academic curriculum and pedagogy, legislations that are proactive for generating age-friendly and sustainable built forms and developments, control and tolerance of hate and terrorism, and increased adaptability to climate change. It must be stressed that the professional and statutory regulating bodies act in one accord for a quantum leap in terms of major revamping, restoring the lost relevance and imparting learner empowerment in the long term survival of the profession.

\section{Evolving academics in architecture}

Education is an ongoing process where there exists no ultimate peaks or limits to the heights one could climb. Educators in architecture; Pilgrims in progress, engaged in the pursuit of architectural education, often find their paths ever challenging and goals never cease enticing, thanks to the depths to be explored and the heights never ascended, especially in the context of cross cultural and increasingly interactive methods in the field of design, intended to facilitate 'assimilation, understanding and reinterpretation' of the aspirations of users. Architects in this process, nurture creativity and originality to establish a meaningful continuum; Architecture. The challenges are even more thanks to globalization and liberalization that open wide the thresholds of every nation around the globe in favor of pluralist, global communities with structures of their own, manifesting differing choices. Such global communities have yet another statement to make as opposed to the traditional ones. Their spatial statements demand a fresh understanding by architects who are engaged in its transformation to acceptable built forms which also provide a mighty challenge for the contemporary field of architectural education.

India; the land of legendary philosophers, well known for her contributions in philosophy, mathematics, medicine, architecture, art and education, throughout the times has established learning centers of great wisdom and learner-empowering pedagogy for which the Gurukulams of the bygone days bear witness. Academics in those centers were founded on the timeless principles of love, sympathy, truth and coexistence. The marvels of Indian architecture; temples, palaces, towns with meticulous planning or even the highly standardized, modular residential timberarchitecture of Kerala are timeless testimonies of its rich heritage. These built forms set in their respective landscapes are encoded with societal considerations and remains symbolic; written texts in space, time and materials, over and above their shelter functions. The designers of such invaluable cultural products of our glorious past were empowered through an immaculate, interactive training system that imparted skill and wisdom in them. Times, values and considerations have changed since then, so too education in architecture. In the days of internationalism designers assumed a new role 'to create another world stripped-off regionalism and symbolism; a city beautiful for people of power and commons alike, mostly based not on user participation but on utopian ideals. Springing from individual genius wherein, the movement hoped to alleviate all drudgery of life by science and scientific designs. In the beginning of the nineteenth century based on 'Ecole des Beaux-Arts' concept; Aesthetics as a geometric property of objects that could be modulated to the required level by the designer, an elementary form of formal education was started in some of the European Schools, where 'Architecture was considered as an extension of Fine Arts' [2]. In the latter phase of industrialization, Walter Gropius established Bauhaus school of design in 1920, aimed to extend comprehensive formal education in Architecture and Industrial design by integrating art, science, craft and technology. Architectural education got institutionalized with curriculum and pedagogy in effecting the much needed training to transform its graduates, afterwards.

Current pedagogical patterns in architecture are evolved over a period of sixty years; commencing in the early forties, without vital development appropriate to the times. Public image of architects then was vague and was thought to be of a makeup man of structures designed by Civil Engineers and later, as a creator of beautiful buildings for an elite class of clientele. But, the expectations from architects were radically changed with the emergence of varied 
housing and other building complexes set in a limited time and resource framework [3]. Naturally, architectural education too, was prompted to display a bias to the building needs of the rich urban middle class. By doing so, architectural education also lost its valuable symbolic nature, sympathetic response to the culture and context and vital interaction among the students and teachers; the modern gurus. A similar bias is witnessed by the recent advent of the MNCs with 'definite, immutable corporate architectural images' that manifest no concern for its context. Contemporary practice has generated structures that are monstrous, plastic which display frozen dynamism thanks to the enormous computing and modelling power and materials and technology. Major projects of Zaha Hadid and Guggenheim Bilbao by Frank O Gehry; an iconic 20th-century architectural work, through 'plasticizing architecture' and 'defying gravity' display strong contrast to traditional humane models although they claim better status for architecture [4]. An introspection is required for evolving an appropriate model for architecture education, discarding the formal images of what 'architecture be like' and aid manifest creative designs to resolve issues of larger realities by 'synergizing architecture with modern materials and techniques and uniqueness of a specific context'. Such a model will produce enabled professionals who have the 'sensitivity, sensibility, skill and analytical capability' with the much needed 'creative and communicative acumen' in translating the spatial needs of the contemporary globalized communities. It is suggested to base the learning of architecture to the ground realities without de-linking it from the practice and research, which is observed even in some developed countries.

\section{Imprint of globalization on academics}

Trends manifest indicate the formation of multicultural, heterogeneous student groups in institutions of mass education whose prime objective is to acquire skills and learner empowerment [5]. Various studies conducted worldwide establish that higher education has to get adapted to the changing requirements of industry, employment patterns, student expectations, socioeconomic and environmental conditions [6]. There prevails an alarming trend among students in abandoning their respective areas of training for want of better job prospects [7]. Compared to the earliest university scenario where students from the uppermost strata of societies only were admitted; indicating lower levels of heterogeneity, contemporary universities admit students without bias of any type namely sex, culture, religion or economic status [8]. Globalization generated the need for mass education and greater institutionalized professional training. Now, students from almost all nations find avenues for education in their chosen fields of study and institutions. Studies conducted by the International Institute for educational Planning, Paris, further establishes the contemporary trends with the increasing number of girl students and students from lower income levels. India too shows increasing female to male ratio and number of students from rural background with lower exposure levels [9]. Industry and the potential employers have their own demands that vary from time to time. Learning habits too, are at variance due to many reasons like lack of time, resource, requirements of convenience and comfort. Recent avenues opened by various universities in Distance Education, E-Learning and OffCampus education stand in proof of their efforts to cope with the growing heterogeneity of student groups. More important is the demand for shorter, but effective programs with added value to its graduates, in the job market. However, a minimum of six years of rigorous academic training is highly recommended leading to integrated M. Arch with option for withdrawal at the end of third year, with a non-practice degree which may be appropriately named as BS. Arch. The learner who wishes to practice has to continue the rest three years with rigorous training in architecture, philosophy, and various micro-specialization areas like symbolism, bio-mimicry, sustainability and built form aerodynamics. Discourse shall be fundamental at this level of education where learners shall engage themselves in independent research papers and research methods in Architecture.

\section{Issues of architectural education}

The increasingly globalized communities with ever increasing digital divide along with other reasons cited above are effecting changes in the roles and responsibilities of architects. Such changes, in turn recast expectations of the prospective students of architecture. The students have higher expectations of rewards for the jobs done especially when compared with their engineering counterparts. It is a matter of concern that even in premiere institutions, $50 \%$ or more of the graduates of architecture turn to software and related jobs, abandoning traditional architectural practice. The lure of the lucrative IT jobs; where one could get much higher rewards, compel the students of architecture to spend their time in acquiring software skills even at the expense of the time to be invested in design and other core subjects of architecture. Young architects are paid a pittance for their works of genius by the exploiting clients, thereby lowering the status, honor and respect of a great profession [10]. Fault cannot be found in doing so for one of the reasons for pursuing education is to secure a self-reliant life [11]. This inevitable deviation would be manifested as lack of interest in architectural studies, which the teachers normally fail to appreciate for it would produce designers of lower caliber and skills. Moreover, prevailing pressing situation compels teachers to dilute the standard of education for want of minimum pass rate necessitated due to survival requirements of institutes. Matching quality and quantity is a big question to be explored and an appropriate model is to be sought for the continued relevance of the profession. Time is ripe now for the architects to stop sleep walking and begin the search for a new model to generate empowered professionals. Year after year, the lack of genuine interest in professional training and research gets reduced and has now reached a peak that demands a revamping of the system of architectural education itself ascribing due importance to present and future scenario of the 'beingchanged' world. It is high time to do away with obsolete syllabus, in favor of relevant areas of architectural, technological, cultural and anthropological studies and application, in order to generate quality architects who possess fundamental knowledge, essential skills and sensibility.

It is disastrous to de-link the profession from the academics but, both must mutually coexist imbibing the fruits of research 
and procuring of research problems from the profession and site. In this age of information revolution, education in Architecture has to incorporate novel methods of information technologies to equip the future generation of Architects. The central aim shall be to make them 'comprehend and understand the interactive processes, make rational comparison of alternatives, quantify issues for making thinking explicit and understandable for others' to take part in the decision making process. It is important to reiterate the participation of the users of built form and development projects in the decision making process through public participation and auditing. In this new order, architects may lose their 'omnipotent image' but, need to be only 'one among the members' of a larger team, yet retaining the essential managerial leadership. Thus, the idea of imparting leadership in future architects calls for a more comprehensive, learner empowering and effective training; an alternate academic model that is central to the making of value added professionals. Therefore, an explicit statement of the purpose of education is essential to enhance the professional credibility which is essential for the strategic long term survival as a profession. Throughout the history of education, architecture as a design subject has always shown lethargy to adapt to the rapid changes in technology and ineptness to incorporate quantification methods, relevant to the techno-cultural states of the concerned society. Plainly speaking, architectural education solely based on individual search alone does not impart comprehensive design education as it grossly lacks information and skills on technology assessment, managerial analysis and legal issues [12]. While technological and managerial skills are essential for effective architectural training, instilling sensitivity and sensibility to artistry, heritage and symbolic cultural systems of society is kernel to understand, reinterpret and transmit spatial messages through architecture [13]. Architecture devoid of the manifestations of culture and values of the society for which it is created, is far less than 'meaningful', especially in the contemporary world caught up in identity syndrome.

\section{Architects -quality vs. quantity}

Though it is important to produce more number of architects to deal with the ever growing needs of a fast developing world with its own specific needs, it is even more important to produce quality professionals who are well-trained to resolve creatively the specific spatial needs of the users in a culturally relevant fashion. It is needless to state that the schools of architecture hence, have to lay importance to understand and reinterpret the heritage and culture in their honest attempts to create worthy architects and architecture. Therefore, the schools have to foster research in architectural anthropology and encourage their students to be 'learning in the midst of the respective culture and its people', not just classroom teaching alone will suffice. The designers shall be encouraged to be in union with people and their culture and to generate creative, yet meaningful designs rather than the utopian beautiful and curious forms that challenge imagination and gravity. Architectural education shall respond appropriately to the global concerns in the fields of disaster related architecture, socio-economic and architectural communication, developing appropriate and ecologically friendly and performing built form standards together with addressing the basic issues of elderly and economically weaker sections that includes appropriate, lowcost quality housing. The education in architecture shall empower architects to learn from self-discovery rather than imparting mere drafting and professional skills, though the latter is important. The products of such an educational system shall be independent and unbiased thinkers who manifest sensibility and sensitivity to the culture and context but not fail to be scientific in their attitudes.

\section{Continuous evaluation for quality graduates}

B. Arch course like any other design oriented course has a more open ended, yearend evaluation system incorporating critical evaluation by external experts at different levels of the program; from sophomore year to the final grand viva-expected to assess the suitability of candidates from the point of view of the industry. Unfortunately, many a times these evaluations starts with data presentation, runs with design presentation and ends up with a bulk of unprocessed data, and meaningless but, excessive use of design verbosity. Evaluators, on the other hand, never attempt to evaluate the candidate's suitability and capability to perform various functions of the Architects as stipulated by the regulating bodies. Though the end product; the final design is important, architectural education shall lay stress on 'continuous evaluation' of the works of students, enabling them constantly to think, analyze and to independently generate appropriate solutions that are culturally relevant. Continuous evaluation system; CES, molds the students to be 'proactive learners', while transforming 'teaching activity into learning activity' through participatory discourse. This makes them aware of their position at any point of time in regard to academic performance and empowerment. CES encourages learners to argue, explore and experiment, leading to self-discovery. Assignments are drawn from the real-life context and focuses on issues relevant to the society. Instilling values in students is kernel in the CES and attendance, discussions, examinations and other prescriptions by teachers is a must and are viewed seriously. CES thus, facilitates students to think, discourse, interact and communicate without bias to develop performance relentlessly along with a strong moral value system.

\section{Changing roles professional bodies in architecture}

Architecture has ever remained a product of human culture and shall remain so in future. Moreover, it is a complex whole comprising of environment, science, technology and people and their comfort. Research in architecture shall focus on the cultural, anthropological, material and technological aspects and the changing trends of any society. It is important to understand the 'communicative value of architecture' and the role of print, media and journalism in its furtherance. It is unfortunate that till very recent times research in architecture was almost void and there prevailed only 'debate on research' that too whether research in architecture exist or not! Academics in architecture shall no more remain inert to research but shall abound in research and quick to integrate the fruits of research in teaching. Only then shall the obsolescence in architectural education could be wiped off and learning be made relevant and joyful. In order to foster research, academic course and curriculum 
shall be redesigned incorporating necessary inputs to establish a strong theoretical base, appreciation for culture and context, user behavior and preferences over technological dominance and search for alternative design models like bio-mimicry. Every school of architecture shall strive to establish its own research and development and train its faculty to be better researchers. The role and contribution of professionals in this context is vital since they represent the interface between academics, research and Industry. Partnership and collaborative ventures in research alone could foster quality and value in students and faculty alike. Only by such novel methods of cooperative ventures the quality and employability of the graduates could be enhanced and increasing disinterest that's exists today, can be removed. It is therefore of immediate importance that professional bodies jointly with academic bodies compel government and industry alike to support research and development. It is also important to develop networking among architectural institutions at national and international levels with student and faculty transfer and sharing of resources to remove obsolescence.

\section{Classroom teaching -problems and prospects}

Universities of the world, especially in the past centuries have enjoyed a very privileged, autonomous position which is made evident by the shortage of information about their structure and activities. The lack of statistical information and data keeps the sociology of higher education still in infancy. Such a situation poses serious constraint for the curious investigator as well on the effective management of institutions. Programs launched by the All India Council for Technical Education like the 'Early Faculty Induction Program' testifies to the non-availability of qualified teachers in Indian context. These questions demand answer in terms of appropriate, creative methods of teaching and learning that springs forth from the right attitude to the changing trends, since 'the students of today are the teachers of tomorrow'. Higher education systems in developing countries labor under a number of disadvantages and with no backlog of experience to draw from. Coupled with it there is growing difference in learning habits and expectation of students due to a steady rise in the number of women and children from working-class families entering higher education, contrary to earlier elite takers in architectural education. Therefore, apart from the traditional academic motives for creating a new curriculum and course pattern, it is vital to look for 'relevance of any course' which is important in today's higher education, thanks to the external pressures arising from the skilled manpower needs of industry and society. It remains a vital question to be answered; whether to perform classroom teaching to impart 'knowledge that transforms' the student or simply 'to secure a pass in examination' in the process of acquiring a degree. While education shall find wider avenues for the expression of the learner's full personality, unfortunately the students are looked upon as mere raw materials on which teachers impose their views, instead of facilitating the spirit of enquiry and dedication to the pursuit of knowledge. It is established beyond doubt that the purpose of communication is to empower and transform the receptor which applies to classroom teaching also, in which case the role of the educator is to lead the students to their self-discovery thereby, 'meaning is acquired and learning happened', rather than the student ends up in 'mugging up' of statements that are mere grammatical constructs [14,15]. Empowerment of receptors is facilitated by the happening of a discourse between them and communicator. Such a discourse never happens unless learners speak through their own questions and awareness. Education shall promote enquiry by learners in different primary and secondary sources. Teachers inducted to teaching without prior professional training poses another serious problem in academic world that, frequently remains in isolation and omitted. Essential mentoring for the young recruits is therefore, inevitable.

\section{Need for learner oriented teaching}

Any shift in teaching with a concern for learning does not accept the 'communication-learning fallacy', which assumes that 'information transmitted to the student is always learned'. Though this was more or less an accepted basis of all discussions of teaching methods, later researches proved it lop-sided with ways of transmission of information to students without exploring too closely what was learned, by whom and at what speed for what purpose. This lead to a passive attitude towards student response: students are seen in a dependent situation, relying on the information thrown at them, whether through the media or 'chalk and talk'. Learning, on the other hand, is an 'interactive, twoway process in which the role and experience of student are vital components'. Here the student contributes and also receives and remains an active partner of the teacher and their perception of what is happening is as important as that of the teachers and his assessment of its value [16]. Learner oriented teaching will consider what experiences will motivate the student and enable him to learn, what ways knowledge can be best structured for a given learner or group, what sequences or modes will present the material most efficiently, what should be the nature and pacing of rewards or penalties, and how a student can be moved from extrinsic rewards to those which are intrinsic [17] Figure 1.

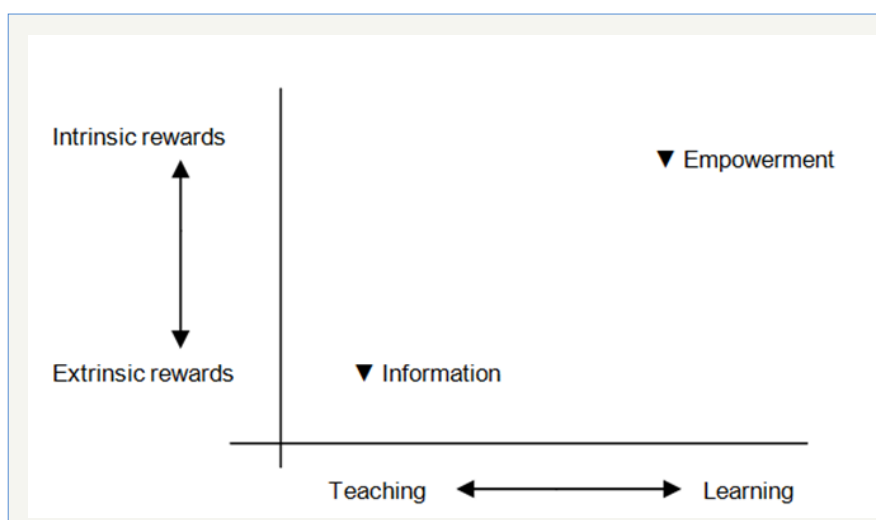

Figure 1: Teaching-learning; information to empowerment.

Learner-based pedagogy leads away from the conventional problems of teaching and learning to much wider issues; to a theory of instruction that seeks to take account of the fact that a curriculum reflects not only the nature of the knowledge but also the nature of the knower and the knowledge-getting process where 
the line between the subject matter and the method vanishes off. It facilitates the dynamic participation of learners which makes possible the transmission of knowledge. Learner-orientation requires a positive change in roles and relationships of teachers, students where teacher herself becomes a learner because she learns more about teaching and the learners begin to assume greater responsibility for their own progress which in turn changes the ecology of the teaching institution by redefining its primary role in terms of learning Figure 2.

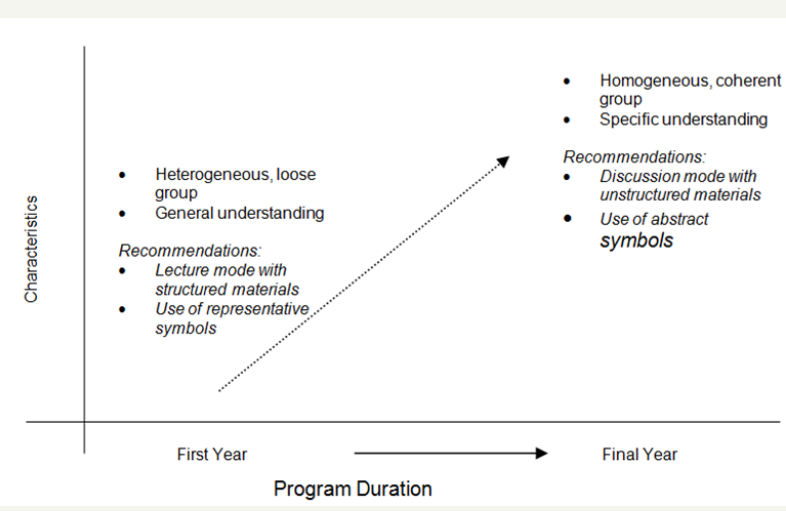

Figure 2: Characteristics-program duration relationships

\section{Search for a new model}

It is high time to search for an effective model for degree programs in architecture. The intake to such programs could be made from a wider student base which could be gradually narrowed down to the precise student group possessing the required level of aptitude, flair and capacity for pursuing education, research and training in architecture. The new model shall be equipped with option for those students who do not meet the criteria to switch over to other appropriate programs with conferred degree at the end of three years. Moreover, diverse options may be made available for students to specialize in appropriate fields like interiors, computer applications, landscape, sustainable designs, green auditing, carbon credits, architectural anthropology, visual design, product design or the like over and above architecture. Further, the program in architecture could also be made integrated and more rigorous with increased duration of six years, leading to professional Master's Degree in Architecture [17]. Such an appropriate revamping alone could bring back the lost relevance to education and practice of architecture prevailing in the contemporary world.

\section{Conclusion}

The study evidences the influence of globalization, science and technology along with other socio-economic and environmental influences on academics and practice of architecture in the contemporary scenario. In academics, trends manifest indicate the formation of multicultural, heterogeneous student groups in institutions of mass education. Increasing levels of obsolescence of the contemporary educational systems in terms of their pedagogy, instructional tools and spaces are a matter of immediate concern. Contemporary architectural education scenario is yet to respond appropriately to the needs of the multicultural, globalized societies, and impart learner empowerment. It is stressed that academics shall respond positively in molding empowered professionals who possess the required sensitivity, sensibility, skill and analytical capability with the much needed creative and communicative powers in translating the complex needs of the contemporary scenario. Importance of research and development along with networking of institutions at the national and international levels with student and faculty transfer and sharing of resources stressed. Problems of classroom communication and importance to develop appropriate graphic tools for classroom communication in order to generate and sustain learner participation are established. Role and responsibility of professional and regulating bodies is vital to securing the much needed goodwill and cooperation with industries and governments to obtain research funds. The importance of learning over teaching, and empowerment through learning in contemporary architectural education is brought out. Moreover, a major revamping is suggested for restoring the lost relevance and imparting learner empowerment to facilitate long term survival of the profession of architecture.

\section{References}

1. Ball MS (2012) Livable communities for aging populations: Urban design for longivity. John Wiley and Sons, Hoboken, USA, pp. 3-19.

2. Abraham G (2005) Adaptive strategies for revamping architectural education for multicultural, global societies with an emphasis on classroom learning. In: George Abraham (Ed.), Seventh International Conference on Humane Habitat, RIZVI College of Architecture, Mumbai, India.

3. Raori VP (1997) Development of architectural education in today's context. Journal of Indian Institute of Architects 62: 36.

4. Sashikant H (2014) Economic Research India Pvt. Ltd, Architecture update, Mumbai, India, 8: 4.

5. MacKenze N (1976) Teaching and Learning: an introduction to new methods and resources in higher education. Second-revised. The Unesco Press and the International Association of Universities, Paris, p. 224.

6. Abraham G (2004) Strategy for revamping architectural education-A critical analysis. In: George Abraham (Ed.), Indian Institute of ArchitectsBangalore Center, National Seminar on Architectural Education, Indian Institute of Architects, Bangalore, India.

7. Bowen J (1986) A history of western education: Ancient world -Orient and Mediterranean 2000 BC to AD 1054. Methuen and Company Ltd., London, 1: 394.

8. Rege AK (1988) Architectural education in smaller towns. Mumbai: Architecture+ Design. A Journal of Indian Architecture 15: 53.

9. Claude B (1997) The prospect for Architectural Education in India. Journal of Indian Institute of Architects 62: 3-7.

10. Mani RS (1999) Educational Ideas and Ideals of Eminent Indians. New Books Society of India, New Delhi, India.

11.Abraham G (1997) Restructuring Strategy for Architectural Education. Journal of the Indian Institute of Architects, Mumbai, India, 62.

12. Krishna KSA (1990) Upgrading Architectural Training. Indian Architect and Builde, Mumbai, India. 
13. Robert H (1985) The Language Gap -How classroom dialogue fails. First. Methuen, London, 1: 232.

14.Kraft CH (1991) Communication Theory for Christian Witness. Orbis Books, New York, USA.

15. David J (1966) The social organization of education. The new media and education: their impact on society. BJBPH Rossi, Chicago, Aldine, USA.
16. Burner JS (1960) The process of education. Harvard University Press, Cambridge, USA.

17. Thomas AM, Cameron D (2005) The Words Between the Spaces: Buildings and Language. Taylor \& Francis, London and New York, UK, pp. 24-30. 